\title{
The effect of emergent technologies on accountant's ethical blindness
}

Karma Sherif. Qatar University. Qatar ksherif@qu.edu.qa

Hania Mohsin. Qatar University. Qatar hania.mohsin@qu.edu.qa

\begin{abstract}
The accounting field has come under scrutiny after a number of high-profile ethical scandals dealing with organizational fraud has been tied to the profession. While several accounting standards have been established to ensure the integrity, objectivity, and professional competency of accountants; the power of the situation and individual motivations are challenges that may ethically blind accountants and result in fraud. In this paper, we explore the combinative effect of three emergent technologies: Blockchain-based, IoT-enabled and AI-empowered distributed ledger on reducing the risk of accounting ethical blindness. We examine how technical features of emergent technologies present both gains and challenges to ethical decision-making for the accounting profession. While some of these challenges can be overcome by adopting all three emerging technologies, others require social and legal interference to avoid the challenges of these technologies.
\end{abstract}

Keywords: Emergent technology, accounting ethical blindness, blockchain, artificial intelligence, internet of things.

\section{INTRODUCTION}

While accountants are perceived as the regulators of the business world, overseeing the validity of financial reports and ensuring their accordance with recognized standards, accounting professionals are often faced with situations where judgment 
can be ethically or legally challenging. Unethical accounting is a growing global concern as companies small and large around the world are entangled in ethical scandals. According to the 2018 report to the nations (ACFE, 2018), accounting poses the highest risk for organizational fraud. The Economist (2014) even warns that:

"If accounting scandals no longer dominate headlines as they did when Enron and WorldCom imploded in 2001-2002, that is not because they have vanished but because they have become routine."

Fraud related to financial statements results in the highest economic loss with a median of \$800,000 (ACFE, 2018, 2019; PwC, 2018).

The accounting field has numerous ethical accounting standards (IAS (Service, 2020), GAAP (Board, 2020), IFRS (Standards, 2020), FASB (Board, 2020)). However, ethical blindness has been a major challenge for compliance leading to manipulations of accounting principles (Smieliauskas et al., 2018). Companies adopting either the US GAAP (FASB) used in the US or the International Financial Reporting Standards (IFRSs) adopted worldwide have been accused of material misstatement of accounting estimates due to unintentional or intentional management bias (Smieliauskas et al., 2018). The weaknesses in financial reporting standards open a back door for unethical behavior, calling for the auditing of the standards themselves and a close examination of how they may facilitate fraudulent and unethical reporting (Amernic \& Craig, 2010).

This paper explores the different ways emerging technologies, like blockchain, internet of things and artificial intelligence, can help moderate ethical blindness in accounting. Such digital technologies will overcome the inadequacy of accounting standards that fail to address the needs of various stakeholders in today's Information Age (Vasarhelyi et al., 2012). This is particularly important because these emergent technologies promise to validate the accuracy of financial reporting and moderate the effect of ethical blindness, thus improving the public image of the accounting profession as a whole.

The paper is structured as follows: we summarize the literature on ethical blindness in the accounting field. Next, we explore how each of the emergent technologies, 
namely blockchain, internet of things, and artificial intelligence, reduces ethical blindness along with the challenges that each of them presents. We then consider the combinative effect of applying all three technologies on reducing ethical blindness and how the whole is greater than the sum of the parts, especially in resolving the challenges posed by the technologies. The paper ends with practical and theoretical implications and directions for future research and practice.

\section{METHODOLOGY}

A detailed literature review was conducted to examine accounting papers on ethical blindness, as well as, information technology and computer science research that cover artificial intelligence, blockchain, and internet of things. Papers in accounting journals that covered any of the three emergent technologies were also reviewed. We obtained more than 500 articles as of December 2020. Using the Web of Science, IExplore, and Scopus databases, we limited our review to articles that covered problems related to accounting ethical blindness and features of the technologies that support accounting ethical standards. After screening the articles that met our requirements, we retained one hundred and ten articles categorized as shown in figure 1.

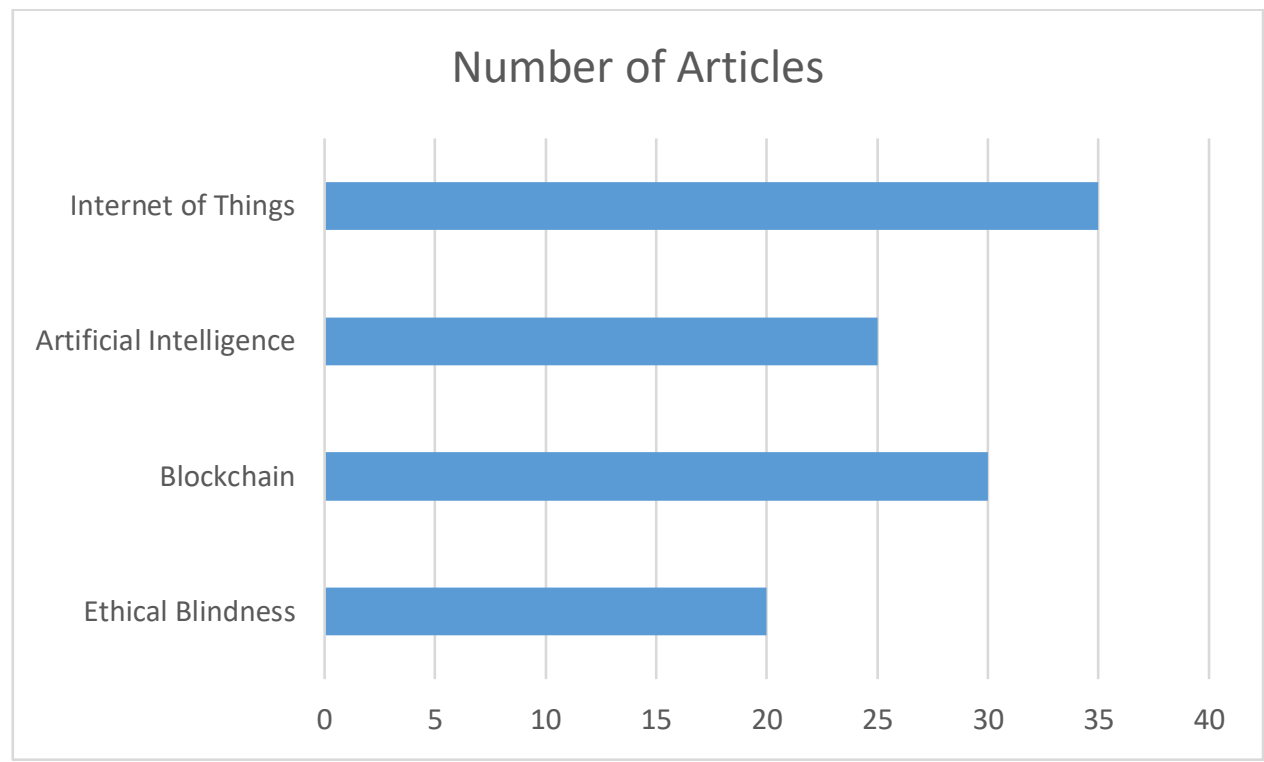

Figure 1. Distribution of Articles by Type of Study 
Articles obtained for ethical blindness were classified based on the type of accounting fraud: misappropriation of assets, manipulation of earnings, and financial statement fraud. Table 1 shows the number of articles retrieved for each type of accounting fraud.

\begin{tabular}{|c|c|c|}
\hline Type of Ethical Blindness & Number of papers & Important Studies \\
\hline Misappropriation of assets & & $\frac{(\text { Hall, 2009; }}{\left.\underline{\text { al., }} ; \frac{\text { Smieliauskas et }}{2018}\right)}$ \\
\hline Manipulations of earnings & 20 & ( $\underline{\text { Hall, 2009; }} \underline{\text { Kelly \& Murphy, }}$ \\
\hline Financial Statements & & $\frac{\text { (Brown et al., 2020 }}{2009)} ; \underline{\text { Hall, }}$ \\
\hline
\end{tabular}

Table 1. Categorization of Articles on Accounting Fraud

For each type of technology, articles were classified based on their coverage of features that support the accounting ethical standards: integrity, confidentiality, objectivity, professional behavior, professional competency and due care. Table 2 shows the number of articles retrieved that support our proposition the emergent technology will help enforce accounting ethical standard.

\begin{tabular}{|c|c|c|c|}
\hline Technology & $\begin{array}{c}\text { Ethical standard } \\
\text { enforced }\end{array}$ & Number of articles & Important references \\
\hline Blockchain & $\begin{array}{c}\text { Integrity, } \\
\text { Professional competency } \\
\text { and due care, } \\
\text { Confidentiality }\end{array}$ & 30 & 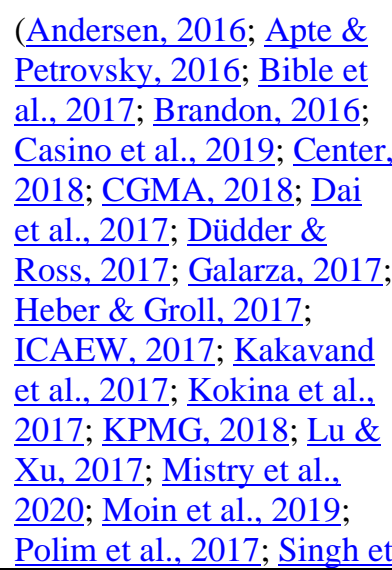 \\
\hline
\end{tabular}




\begin{tabular}{|c|c|c|c|}
\hline & & & $\begin{array}{l}\text { al., 2020; Tang et al., } \\
\text { 2019; Vaidyanathan, 2017) }\end{array}$ \\
\hline IoT & $\begin{array}{c}\text { Integrity, } \\
\text { Professional competency } \\
\text { and due care, } \\
\text { Professional behavior, } \\
\text { Objectivity }\end{array}$ & 25 & $\begin{array}{l}\text { (Chui et al., 2010; Dai \& } \\
\text { Vasarhelyi, 2016; Friess, } \\
\text { 2016; Galarza, 2017; } \\
\text { ICAEW, 2019; Lindqvist } \\
\text { \& Neumann, 2017; Mistry } \\
\text { et al., 2020; Moin et al., } \\
\text { 2019; Moll \& } \\
\text { Yigitbasioglu, 2019; } \\
\text { Murphy, 2015; Salman, } \\
\text { 2015; Schuh et al., 2014; } \\
\text { Singh et al., 2020) }\end{array}$ \\
\hline AI & $\begin{array}{c}\text { Integrity, } \\
\text { Professional competency } \\
\text { and due care }\end{array}$ & 35 & 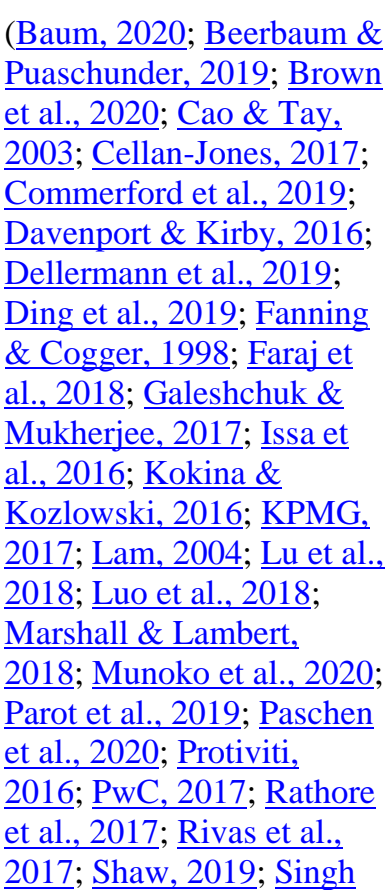 \\
\hline
\end{tabular}




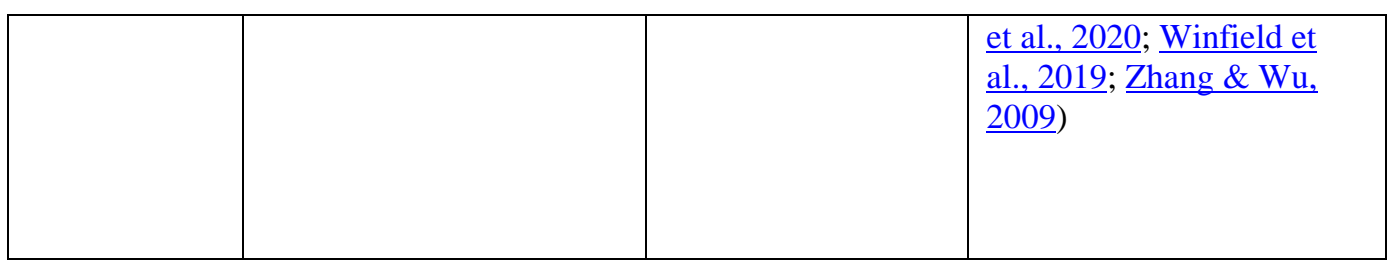

Table 2. List of Ethical Standards Supported by Emergent Technologies

The final stage of our methodology mapped features of the emerging technology to the accounting ethical standards it enforces as well as threats the technology poses to the standards (Table 3).

\section{ETHICAL BLINDNESS IN ACCOUNTING}

Accounting fraud is the most reported type of fraud mounting to 59 percent of all fraud committed in 2020 ( $\mathrm{PwC}, 2020$ ). Majority of the accounting scandals are related to misappropriation of assets, manipulation of earnings, and financial statement fraud. Contrary to the general belief, accountants charged with occupational crimes are first time offenders, with a high social status within their organizations and a long tenure (Fisher, 2015).

Accounting fraud has been attributed mainly to ethical blindness (Kranacher \& Riley, 2019), a term defined as "the decision maker's temporary inability to see the ethical dimension of a decision at stake."(Palazzo et al., 2012). Humans in general are prone to ethical blindness as ethical issues are often not readily available in memory, causing humans to react to situations first then reason through their decision after (Hall, 2009). This is primarily because situational factors unconsciously subdue the moral identity, putting more weight on short term benefits than the long-term negative consequences (Aquino et al., 2009). When exposed to ethical dilemmas, humans overestimate their ability to act ethically and fail to realize the power of the situation, resulting in a conflict between the standard of behavior they are expected to comply with and the actual behavior that is committed (Ding et al., 2019). Individuals may fall prey to automatic rationalization and reason that an unethical behavior is for the greater good (Kranacher \& Riley, 2019) without taking the time to reflect on the decision making (Laing, 2016).

Ethical blindness has been reported as an unintended outcome of professional accounting standards, especially when the standards provide little guidance on 
acceptable risks of future forecasts and accounting valuation estimates (Smieliauskas et al., 2018). The standards tend to focus more on factual accuracy in financial reporting than on ethically representing future events (Menzefricke \& Smieliauskas, 2019). As a result, accountants manipulate data to represent an exaggerated economic reality to impress interested parties. They engage in gray earning management practices that is opportunistic but still immoral (Vladu et al., 2017).

The high rise in accounting occupational fraud led researchers to examine the various causes of ethical blindness (Mansor, 2015). One of the traditional theories employed to explain the causes of fraud is the theory of "Differential Association" (Southerland, 1947). The theory states that committing fraud is a learned social behavior. Social interactions with others may lead to one or more of the three elements of the fraud triangle (Cressey, 1953; Kranacher \& Riley, 2019): Pressure, opportunity, and rationalization. Pressure is an urgent perceived need to commit fraud. Financial pressures to report high earnings have been linked to violations of assigned responsibilities (Cressey, 1953), a major problem in capitalistic societies (Coleman, 1987). A survey by the Center for Audit Quality (2010) revealed that corporate governance are over-concerned with results at the expense of validating the processes carried on to achieve these results. Decision-making in a business context puts a lot of emphasis on the financial perspective which may compromise ethical standings and cause people to be ethically blind (Joffe-Walt \& Spiegal, 2012). These findings are supported by Prospect theory (Kahneman \& Tversky, 2013) and the theory of Motivated Reasoning (Kunda, 1990) which imply that humans tend to be biased to a course of action that is more aligned with the reference point of their personal or organizational goals. Accordingly, manipulations of operating cash flows and discretionary accruals occur to meet fixated forecasts (Murphy \& Dacin, 2011). The pressure causes the decision maker to neutralize the immoral aspect of the decision resulting in a significant number of young executives in high-risk companies rationalizing unethical behavior and engaging in aggressive financial reporting as they feel more pressured to achieve targets (Schnatterly et al., 2018). 
Opportunity is the second leg of the fraud triangle representing a chance with a limited window span to commit fraud (Dellaportas, 2013). Examples of opportunities are hierarchical positions within an organization or possession of highly valued technical skills to manipulate internal controls (Wolfe \& Hermanson, 2004). Given the trust they enjoy within their organization, experienced accountants may also outweigh the positive outcome associated with an opportunity and will tend to rationalize their use of innovative financial accounting (Schnatterly et al., 2018).

The third leg is rationalization which refers to the justification an individual advances to validate a decision without feeling guilty of being socially deviant (Cressey, 1953; Fisher, 2015). It involves externalizing the negative effect associated with an unethical behavior to a source away from the self (Snyder \& Higgins, 1988). While personal characteristics, moral values, and narcissism tend to increase the chance of rationalizing fraud, corporate culture and tone at the top are strong determinants of rationalization (Dorminey et al., 2010). Companies that engage in high-risk initiatives are also more likely to rationalize corrupt behavior (Karmann et al., 2016).

Rationalization plays an important role in ethical blindness, as humans in general tend to rationalize behavior that serves their interest (Epley \& Caruso, 2004). The repeated use of rationalization strengthens the ethical blindness (Hall, 2009; JoffeWalt \& Spiegal, 2012) to become the new reality without hope of being disclosed (Hall 2009). This is particularly true when standards are ambiguous giving accountants the opportunity to creatively exploit the ambiguity at the expense of ethical decision-making (Hall 2009).

A suite of technological tools has recently been introduced with technical features that can combat fraud. Among these are blockchain, artificial intelligence, and internet of things. The combinative effect of the three technologies increases the chances of detecting financial reporting fraud (ACFE, 2019). Three of the Big 4 accounting firms are investing $\$ 9$ billion in $\mathrm{AI}$ in an effort to make the technology part of the identity of audit processes, creating internal controls to prevent fraud with a rationalization of the risks that an accountant may take (Issa et al., 2016; Winfield et al., 2019). By providing the warning signs of fraud, organizations are 
strengthening the corporate ethical and moral values and helping nurture an ethical culture.

In this paper, we explore the features of these emergent technologies and their potential power to reduce ethical blindness. Table 3 provides a summary of the capabilities each technology embodies to enforce ethical standards and highlights the challenges that each technology poses to the accounting code of ethics.

\section{TECHNOLOGY OVERVIEW}

\subsection{Blockchain}

Blockchain is near real-time decentralized distributed ledger of transactions conducted by peers on a digital network (Kakavand et al., 2017). Every peer on the blockchain acts as a "node" and maintains an identical copy of the ledger, with no centralized control over the chain (Dai et al. 2017). Peers validate transactions and post them to the blockchain (Bible et al., 2017; ICAEW, 2017). Once transactions are posted, the record becomes permanent and cannot be altered. This is due to the use of cryptography that links the blocks together. Every block is identified by a cryptographic hash that renders the whole blockchain invalid in case changes are introduced after posting (Andersen, 2016; Brandon, 2016; Dai et al., 2017).

Nodes interact with the blockchain network via a pair of private/public keys. Private keys are used to gain accessibility to private digital assets as well as submit transactions for verifications. Public keys on the other hand are used to address nodes or access public information on digital assets (ICAEW, 2017; Vaidyanathan, 2017). The neighboring peers validate incoming transactions using a predetermined consensus mechanism to validate or discard transactions. The blockchain is reliable in that it has no single point of failure. In case of failure of any one node, all the other participants operate and maintain system availability (Andersen 2016; Vaidyanathan 2017; ICAEW 2017). 


\begin{tabular}{|c|c|c|c|c|c|}
\hline Technology & Capability & $\begin{array}{l}\text { Application } \\
\text { in Accounting }\end{array}$ & $\begin{array}{l}\text { Ethical } \\
\text { standard } \\
\text { enforced }\end{array}$ & $\begin{array}{l}\text { Challenges } \\
\text { of } \\
\text { technology }\end{array}$ & $\begin{array}{l}\text { Ethical } \\
\text { standard at } \\
\text { risk }\end{array}$ \\
\hline Blockchain & $\begin{array}{l}\text { Immutability, } \\
\text { Transparency, } \\
\text { Assurance, } \\
\text { Programmability, } \\
\text { Privacy, } \\
\text { Decentralization }\end{array}$ & $\begin{array}{l}\begin{array}{l}\text { Distributed } \\
\text { general ledger, }\end{array} \\
\text { Automatic } \\
\text { transaction } \\
\text { reporting, } \\
\text { Smart } \\
\text { contracts for } \\
\text { payments, } \\
\text { fines, quality } \\
\text { assurance }\end{array}$ & $\begin{array}{l}\text { Integrity, } \\
\text { Professional } \\
\text { competency and } \\
\text { due care, } \\
\text { Confidentiality }\end{array}$ & $\begin{array}{l}\text { Separation } \\
\text { between } \\
\text { physical and } \\
\text { digital } \\
\text { assets }\end{array}$ & Integrity \\
\hline IoT & $\begin{array}{l}\text { Real-time } \\
\text { capability (self- } \\
\text { sensing), } \\
\text { Interoperability } \\
\text { (augmented } \\
\text { intelligence), } \\
\text { Virtualization, } \\
\text { Decentralization }\end{array}$ & $\begin{array}{l}\begin{array}{l}\text { Automated } \\
\text { stock } \\
\text { checking, }\end{array} \\
\text { Asset Analysis } \\
\text { Revenue } \\
\text { Analysis and } \\
\text { Audit, } \\
\text { Asset } \\
\text { Utilization }\end{array}$ & $\begin{array}{l}\text { Integrity, } \\
\text { Professional } \\
\text { competency and } \\
\text { due care, } \\
\text { Professional } \\
\text { behavior, } \\
\text { Objectivity }\end{array}$ & $\begin{array}{l}\text { Privacy } \\
\text { Security }\end{array}$ & Confidentiality \\
\hline AI & $\begin{array}{l}\text { Machine } \\
\text { learning, } \\
\text { Prediction } \\
\text { Forecasting, } \\
\text { Assistive } \\
\text { intelligence, } \\
\text { Augmenting } \\
\text { intelligence, } \\
\text { Autonomous } \\
\text { intelligence }\end{array}$ & $\begin{array}{l}\text { Fraud } \\
\text { detection, } \\
\text { Asset } \\
\text { evaluation, } \\
\text { Revenue } \\
\text { projection }\end{array}$ & $\begin{array}{l}\text { Integrity, } \\
\text { Professional } \\
\text { competency and } \\
\text { due care }\end{array}$ & $\begin{array}{l}\text { Bias of AI } \\
\text { algorithms }\end{array}$ & Objectivity \\
\hline
\end{tabular}

Table 3. The effect of emergent technologies on accounting ethical standards 
Another distinguishing feature of blockchain is the smart contract embedded in its infrastructure to automate business processes. Smart contracts are programmable code that can create automatic journal entries when triggered. A key requirement of the smart contract is ensuring that the correct business logic is implemented and the interface with external data sources which trigger business transactions is secured (CGMA, 2018; ICAEW, 2017).

To maintain the privacy of an organization's general ledger (GL) accounts, we expect the blockchain architecture to be permissioned as opposed to the original bitcoin blockchain which is open to the public. Participants can download the software and join the network as peers thereby simply offering their computer processor as a node. On the other hand, permissioned or private blockchain restricts participation to those permissioned to join (KPMG, 2018; Vaidyanathan, 2017).

The Distributed Ledger Technology (DLT) is a game-changer for the accounting profession, eliminating the need to replicate information across multiple databases (Andersen, 2016). It speeds up information sharing and significantly reduces human error. Improving the efficiency and effectiveness of financial reporting and auditing allows accountants to divert attention to more riskier transactions while the blockchain architecture conduct routine auditing in near real time (Bible et al., 2017). The technology results in "triple entry bookkeeping" where every transaction results in a debit and a credit entry along with a cryptographic hash, which verifies the transaction and replaces the need for an independent central validator (Dai et al., 2017). Traditionally, auditing requires sampling of a company's accounting records. With the blockchain, auditing a company's financial status would be less necessary if all of the transactions that underlie the status are visible on the blockchain.

Based on the architecture of the blockchain, many of the endorsed professional accounting ethics standards can be easily upheld. Characteristics like decentralization, immutability, verification, and traceability align well with required accounting ethical standards and increase the capacity of accountants to make ethical decisions (Tang et al., 2019). Below, we examine each characteristic and how it supports the codes of accounting ethical standards. 
Immutability: According to (Kokina et al., 2017), blockchain technology ensures the integrity of all transactions added as a block. This is achieved through a unique cryptographic hash that is deemed invalid if any attempt is made to tamper with any transaction in a block. This is because the change will result in a different computation of the hash invalidating the whole blockchain, hence the terms immutable and permanent give accounting stakeholders a source of trust (Andersen, 2016).

Transparency: Every ledger entry of the blockchain is linked to the previous transaction so that it is retraceable across its full history. Different stakeholders can retrieve disconnected information that can be easily integrated to generate financial statements in a short period of time (Moll \& Yigitbasioglu, 2019). The financial statements will have an audit trail for all underlying transactions providing transparency and building trust in a trustless accounting ecosystem (Casino et al., 2019).

Assurance: The blockchain is also beneficial for fraud prevention and detection. Financial statements can be easily verified as every single transaction posted to the blockchain represents a sufficient audit evidence, so that any type of misappropriation can be easily detected by tracing through posted transactions. In addition, real-time availability of the ledger gives the auditor continuous visibility and monitoring of a company's records ensuring the integrity of financial data (Dai et al., 2017).

Programmability: Smart contracts automate the accounting bookkeeping and supporting accountants to act competently and professionally. As the blockchain automatically records journal entries, the smart contract self-executes, without the need for reconciliation. These benefits will help reduce the chance for financial fraud and improve the efficiency of regulatory and compliance activity which will help resolve some issues of ethical blindness pertaining to the ambiguity in current auditing standards (ICAEW, 2017; Vaidyanathan, 2017).

Privacy: the blockchain architecture maintains the confidentiality and privacy of sensitive accounting data through the public-key cryptographic verification method. Also, accessibility can be controlled to where full access is limited to 
regulatory bodies; while partial access is granted to auditors and clients as defined by their roles and responsibilities (Moll \& Yigitbasioglu, 2019).

Independence (decentralization): The blockchain architecture is designed to be a decentralized database. Every node on the network reads, verifies, and updates transactions to the chain, ensuring objectivity of the data posted (Dai et al., 2017).

\section{Challenges of Blockchain}

One of the biggest challenges that the blockchain poses to the integrity of accounting practices is the separation between the digital and physical world. While the technology validates transactions, it is difficult to validate the nature of the transaction in terms of its legality, correct classification in the financial statement, or relatedness to side agreements that are "off-chain" (Bible et al., 2017). While rules can be embedded in a smart contract, the legal systems need to grant smart contracts the same power granted to paper and electronic contracts, and to define punishments for violating its provisions.

Another challenge is the correct valuation of assets involved in financial transactions. Auditors cannot verify that the valuation posted on the blockchain reflects the actual historical cost. Audit procedures will still be needed to validate management's estimates, even when related transactions are posted to the blockchain (Bible et al., 2017).

\subsection{Internet of things}

The internet of things (IoT) is transforming the physical world into an information system (Chui et al., 2010) where self-sensing and self-acting physical assets can automatically record values (Lindqvist \& Neumann, 2017). Self-sensing is actualized through asset embedded sensors that transmit accounting data in realtime, allowing accountants' true viability of an asset performance (Dai and Vasarhelyi 2016). Sensory data also helps the proper valuation of assets by providing real measurement of utilization and maintenance that accurately reflect on the health of an asset and the appropriate selection of depreciation methods (Moll \& Yigitbasioglu, 2019). Accurate costing will replace many of the overhead allocations (Krahel \& Titera, 2015) and physical assets will autonomously issue alerts to assess and prevent an overvaluation in real time. In addition, devices can 
share information with each other eliminating the need for an intermediary (Mistry et al., 2020). Given the low cost of sensors, data collected from multiple sources can provide accountants with a more comprehensive view of operations from a distance supporting the objectivity of decisions.

The use of IoT will increase the integrity of the accounting records through four main design features of the technology:

Real-time capabilities: the ability of IoT devices to collect and transfer data in realtime will improve asset tracking and optimize asset usage, which are key challenges of the accounting audit. The ability of IoT to feed ERP systems and data warehouses with real-time data will ensure the integrity of the audit process (ICAEW, 2019; Murphy, 2015). Automatic data collection at the source, without human intervention, will also support the objectivity of accounting data. Accountants will also have greater visibility into risks allowing them to take quicker remedial steps when fraud is detected or operations exceed specified tolerance limits (Murphy, 2015).

Interoperability: In addition to self-sensing and self-acting, IoT devices are capable of sharing information with other devices to collectively create augmented intelligence to uncover anomalies in the data exchanged across systems and devices from the different business partners (suppliers, customers, banks and other business entities) in real time (Dai and Vasarhelyi, 2016). The interoperability across IoT devices will provide auditors with the transparency needed to validate transactions while also supporting accountability: two important features needed to achieve accounting integrity.

Virtualization: Information transmitted by IoT devices are fed into digital models representing a virtual copy of the physical objects (Friess, 2016). These information-enhanced models provide two distinct benefits to accountants: a) they are a digital twin of the physical objects and thus can validate the accuracy of ERP systems; and b) they can detect early problems with assets or business processes as real data are analyzed (Dai and Vasarhelyi, 2016). As such, virtualizing the physical world will support the integrity as well as the professional competency and due care of managerial accountants who can now act diligently to improve the utilization of resources and ensure organizational performance is optimized. 
Decentralization: The next generation of IoT devices are designed to have their own computing capabilities, which will enable the decentralization of decision-making at the device level. Given the frequent changes in market demand for customization, the decentralization of decision-making will help products internally control their own configuration based on information from the environment. The ability of the machine to analyze data and detect abnormalities will assist in maintaining the objectivity of the auditors, an essential ethical standard that protect financial reporting from conflict of interests or unjustifiable influence of others (Schuh et al., 2014).

\section{Challenges of IoT}

One of the key factors actualizing the promises of IoT for accounting is the $5 \mathrm{G}$ telecommunication infrastructure (Mistry et al., 2020) that solves the problem of latency and provides accountants' real-time access to data and interaction with physical assets. However, two major challenges defy the ability of IoT technology to support accounting ethical standards: security and availability (Mistry et al., 2020). The majority of IoT-devices depend on centralized cloud servers to store and analyze their own data posing the threat of single point of failure, where all data from physical assets can be inaccessible if the cloud server is down, forcing accountants to use estimates of value. Assessing the resilience of IoT systems and establishing appropriate policies to handle failure and recovery must be considered to manage the risks associated with IoT adoption (Salman, 2015). In addition, the lack of strong security standards at the device level exposes the whole accounting system to the threat of multiple points of entry where attackers can exploit vulnerabilities and get unlawful access to manipulate accounting data.

Apart from technological challenges, IoT represents a paradigm shift of how people perceive the technology and collaborate with it. The dependence on IoT devices for data collection and analysis may represent a psychological threat to employees; a change that needs to be carefully managed (Galarza, 2017; Murphy, 2015) through education and training of how IoT can support asset tracking and valuation (Salman, 2015). 


\subsection{Artificial intelligence}

Artificial intelligence (AI) is defined as "the capability of a machine to imitate intelligent human behavior" (Merriam-Webster, 2020). Large data sets of historical data are used to train AI models to identify patterns and recognize relationships between variables to predict outcomes. When the prediction are not accurate, AI models reinforce their learning and evolve to improve their accuracy (Shaw, 2019).

The use of AI in accounting dates back to the 1980s focusing on the analysis of financial reports (Lam, 2004), detection of fraud (Fanning \& Cogger, 1998), and prediction of future performance (Galeshchuk \& Mukherjee, 2017; Parot et al., 2019). The Big 4 audit firms have heavily invested in AI to assist in audit decisionmaking and validate accounting documents (Issa et al., 2016). (PwC, 2017) examined the evolution of AI applications in accounting, starting from being assistive to augmenting and finally autonomously conducting accounting tasks. These tasks range from review of general ledgers to ensure compliance with accounting standards to monitoring internal controls for fraud detection. AI has also developed the capability to review unstructured data in real-time and provide a concise analysis of numerical, textual, and visual data (Paschen et al., 2020). As such, AI has been labeled cognitive computing capable of selecting a course of action rather than simply following a programmer's instructions. AI models have emerged to exhibit deep learning generating their own hypothesis and modifying them when new evidence emerges; a feature known as reverse inferencing supporting continuous improvement of decision making while ensuring compliance with the different laws and regulations particular to each industry (Marshall \& Lambert, 2018).

It is worth noting that $\mathrm{AI}$ is not intended to replace accounting professionals but rather to augment their intelligence with the ability to explore complex, voluminous and volatile data (Kokina et al., 2017). This is particularly relevant for novice accountants with limited professional experience. Teaming up with AI will support the democratization and federation of accounting expertise. (Kokina \& Kozlowski, 2016).

Several AI techniques have been employed to classify and predict financial metrics. Support vector machine, artificial neural networks, and decision trees have 
achieved remarkable accuracy in predicting future asset price movements (Cao \& Tay, 2003), exchange rates (Rivas et al., 2017), and stock prices (Zhang \& Wu, 2009). Given the latest advances in AI and the design of ensemble models, more complicated tasks in finance and accounting can be carried out at a far greater accuracy than by human experts. In a study comparing Machine Learning (ML) models and managers' estimation of insurance losses, ML models were significantly more accurate than humans with no manipulation of data as analysis of training data is consistent and systematic (Cellan-Jones, 2017). Another benefit of AI is its ability to process unstructured data like audio, video and images and extract insights to support better decisions (Ding et al., 2019).

A clear division of labor between humans and machine will require the evaluation of tasks in terms of maturity, data availability and repetitiveness (KPMG 2017; Protiviti 2016). Tasks that require the consideration of contextual data and a higher level of critical thinking remain within the realm of human judgement (Davenport \& Kirby, 2016; KPMG, 2017; Protiviti, 2016). An understandable advantage of humans over machines is the ability of experts to apply forward thinking to future estimates, taking into consideration expected changes in the state of the economy which machines apparently ignore (Dellermann et al., 2019). ML estimates can thus serve as a first measure for accountants to review. They can also be used as a benchmark against which a case manager can compare human estimates and reconcile if the two are significantly different (Ding et al., 2019).

With respect to ethical blindness, ML can help accountants avoid several intentional and unintentional fraud activities when preparing financial statements (Brown et al., 2020). The latest development in AI capabilities of understanding text, speech and images can strengthen internal controls to support accountant's situational awareness (Ding et al., 2019). Recommendations from AI machines at the time of accounting decision making will help activate ethical standards and minimize the risk of aggressive accounting. Based on the focus theory of normative conduct, recommendations can help mobilize injunctive norms that dictate "what ought to be" done (Cialdini et al., 1990). This will be especially important for organizations where the ethical norms are weak, or accountants are more inclined to adopt aggressive accounting (Kelly \& Murphy, 2019). AI machines can efficiently 
conduct ratio analysis and statistical techniques to identify unethical practices, like earning manipulation, and assess its magnitude.

\section{Challenges of $A I$}

One of the challenges that accounting firms may face in adopting AI throughout accounting business processes is the clear division of labor between humans and machines (Kokina \& Kozlowski, 2016; Luo et al., 2018). The role of AI in Accounting is a source of energetic debate, questioning whether the objective is to support or to influence human decision making (Beerbaum \& Puaschunder, 2019). A major concern of accounting professionals is that AI will bound human actions and reduce their discretion (Faraj et al., 2018). Accountants will need to adopt a new working model to delegate accounting tasks to the machine in order to improve the marketability of the profession (Kokina et al., 2017). Collaboration between humans and machine will require accounting personnel to understand the AI black box and to be aware of the unjustifiable discrimination against algorithms. Recent studies have highlighted the threat of algorithm aversion where the ethical blindness of auditors lead them to ignore AI alerts and misrepresent accounting data (Commerford et al., 2019).

The ability of AI to uphold the accounting ethical standards will depend largely on how it is designed. This is mainly because the moral behavior of an artificial agent is heavily affected by the moral behavior of the human designer (Munoko et al., 2020). As such, many of the accounting ethical standards require that AI be developed with greater transparency regarding how data is analyzed. Along the same lines, fairness and objectivity will depend mainly on the diversity, inclusion and equality in the representation of data analyzed to avoid unwanted bias and unintentional harm (Singh et al., 2020). To enforce confidentiality and protect the privacy of data, AI must be designed to govern access to data by internal auditors, customers, third party and governmental agencies. While "dual use" of data may be unavoidable, establishing governance structure will help reduce the risks for maintaining privacy. Another source of concern is the ethical frameworks incorporated within these systems. Which ethical view should ML systems adopt? The ethical view of the designer? or the aggregated ethical views of society (Baum, 
2020)? The debate called upon the AI community to make the design rationale of ML systems transparent to the public.

Digital and physical world synchronization Secure loT

Explainable Al
Blockchain based, IoT enabled, Al empowered

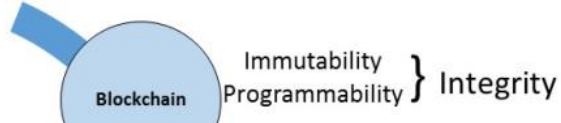

Figure 1. Emergent technologies and Accounting ethical standards

\subsection{The combinative effect of emerging technologies}

The Institute of Chartered Accountants in England and Wales (ICAEW, 2019) has named the combination of IoT, blockchain, and artificial intelligence the "ABCD" of technologies. The A refers to the artificial intelligence that works on Data collected by IoT devices and protected by the blockchain technology that safeguards against the Cyber threats (ICAEW, 2019). The combinative effect of the technologies (Figure 2) will afford a level of transparency that will help reduce the information asymmetry between accountants and regulators and deter against the manipulation of information and the misrepresentation of financial states (Polim et al., 2017); (Singh et al., 2020) providing better financial visibility and reducing ethical blindness (Moll \& Yigitbasioglu, 2019). It will also free the accountants from routine tasks like asset monitoring and allow them time to focus on more critical accounting tasks (Tang et al., 2019). 
The use of the decentralized blockchain architecture to post information collected from IoT devices will help overcome the challenges of single point of failure (Mistry et al., 2020) where the unavailability of one or more nodes does not affect the whole system. The sharing of information across the nodes guarantees the accessibility of data even when some of the nodes are disrupted. In addition, the use of smart contracts on the blockchain allow rules and regulations to be automatically triggered based on information provided by the IoT devices and reflecting an accurate evaluation of assets while ensuring the authenticity and security of the transaction (Tang et al., 2019). The execution of the smart contract will lead to objectivity as accounting rules are enforced independent of any human intervention. Adopting the blockchain infrastructure will overcome many of the shortcoming of IoT applications in terms of lack of accuracy, low latency and focus on centralization.

A blockchain-based distributed ledger that is AI empowered will alert auditors and other relevant stakeholders of abnormal transactions in near real-time while giving them access to immutable audit evidence (Bible et al. 2017). AI can be distributed across the different layers between the cloud and device to improve security (Moin et al., 2019). It will thus help accountants share customer information in a secure and trusted manner without the need for third party verification. The use of blockchain will also ensure that the data shared from multiple sources and fed to the AI machine is authentic and transparent creating an explainable AI and increasing its level of trust and understandability (Singh et al., 2020). This is an important requisite for AI to be ethical (Bostrom \& Yudkowsky, 2014) and to be able to support a smart environment that is constantly nudging accountants to act ethically (Apte \& Petrovsky, 2016; Düdder \& Ross, 2017; Heber \& Groll, 2017; Lu $\& \mathrm{Xu}, 2017)$.

Given the amount of data that can be collected by sensors, AI capabilities are required to make sense of the IoT data. Applications of deep learning will provide the necessary analysis for the accountants to make accurate predictions of the value of tangible and intangible assets resulting in fair value accounting. AI capabilities can continuously monitor and analyze the accounting data flow, calling attention to anomalies and exceptions while suggesting corrective action (Dai \& Vasarhelyi, 
2016). Embedding intelligence at the IoT device level will secure access to the device and control activities to protect data privacy, adding extra resilience and defense against cyberattacks (Singh et al., 2020). The analysis and visualization of data will help recognize patterns and red flag outliers in real-time to provide an effective and efficient data-assurance (Rathore et al., 2017).

One key observation is that the normalization of these technologies within organizations will require that the three technologies to work in tandem. By combining blockchain technology with $\mathrm{AI}$ and IoT, accountants can overcome many of the shortcomings that each technology by itself present. The combinative effect will help reduce ambiguities and provide the necessary transparency that will highlight legitimate action in a given situation making it difficult to accept fraud normatively or cognitively (Singh et al., 2020). Figure 3 proposes that the combinative effect of the three technologies will help reduce ethical blindness and the rationalization of unethical behavior in the presence of an opportunity to benefit from unethical behavior or pressure to act unethically.

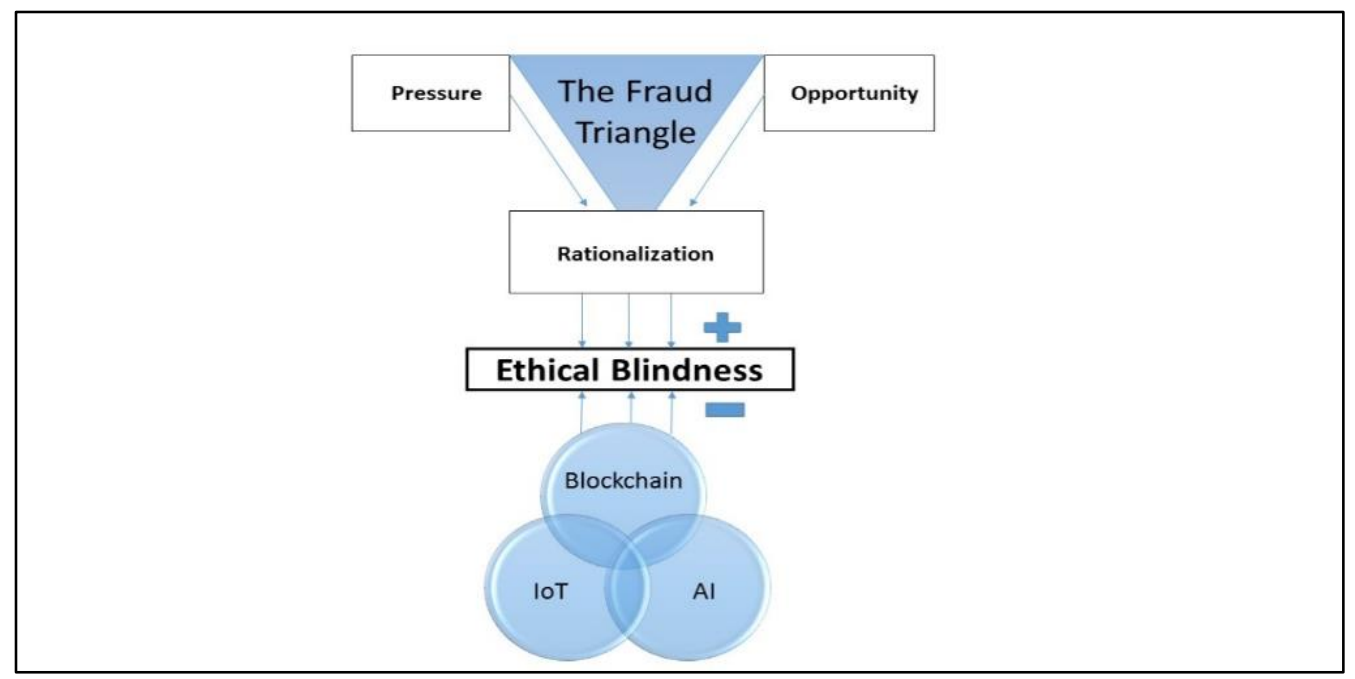

Figure 2. The opposing effect of the fraud triangle and emerging technologies on ethical blindness

\section{Implications}

The adoption of emergent technologies that support the accuracy and transparency of accounting records will have significant implications on ethical accounting 
standards. Our proposal of combining a number of emergent technologies to reduce the effect of ethical blindness is in accordance with the assertion of focus theory of normative conduct which hypothesizes that ethical standards will negatively reduce ethical blindness when they are activated irrespective of the ethical norms within an organization. While previous research has established the effect of organizational ethical norms on the choice of aggressive accounting methods, recent studies have demonstrated that receiving recommendations at the time of decision making will activate ethical norms and reduce aggressive reporting (Kelly \& Murphy, 2019).

We expect accountant's moral intensity to increase as a result of the combinative effect of these emerging technologies, especially when the decision can be morally problematic. As discussed earlier, each of the emerging technologies will intervene to activate an ethical standard that will create moral awareness of the risks associated with the decision. While accountants may realize on their own that a situation is morally intense, accountants may not necessarily choose to act ethically. However, with the technological interventions, the perception of moral intensity will bare more weight on moral intent making it less likely for the accountant to ignore. The underlying rational is that the technological interventions will increase accountant's ethical awareness and moral intent, thus improving the decision making process that occurs daily on client engagements (Shawver \& Miller, 2017). The combinative effect of these technologies will help reduce the unjust power of accountants to pursue self-interest and engage in pernicious accounting practices (Vladu et al., 2017).

We expect, over time, the autonomy of the technology to increase over the expert power of the accountant. The transparency afforded by the blockchain will help reduce any possible collusion between the accounting firms and their clients. The architecture will reduce the number of decision makers handling an accounting engagement as the blockchain encodes rules and automates several decisions. While smart contracts will minimize the risks of data manipulation and reduce the number of ethical misconduct, it will also reduce cost and increase efficiency, allowing accountants more time spent on better understanding of the client's environment (Tang et al., 2019). It is thus expected that some accounting professionals will resist 
the adoption of these technologies as they feel threatened of losing control and power (Tang et al., 2019). Accounting firms will need to adapt to the shift from the accounting governance to the smart contract governance where decision making relies heavily on the computing power of the blockchain and fueled by data collected by IoT devices and churned into augmented intelligence supported by AI. However, the question of accountability needs to be addressed on how it will be shared between the human and machine where the accountant accepts the responsibility of improving the outcome of AI (Moll \& Yigitbasioglu, 2019).

Despite promises of reducing ethical blindness, these emergent technologies have raised a number of concerns. A major concern of the individual and collective impact of these technologies is the security and privacy of data (Singh et al., 2020). Accounting professionals need to identify what data could be shared with others to increase the intelligence in auditing tasks and what data needs to remain confidential (Tang et al., 2019). Of a specific concern is the threat of revealing the identity of a client and compromising the security and privacy of their data (Singh et al., 2020).

With respect to the blockchain, the set of rules governing all transactions are rigid and thus special attention needs to be given to the governing structure to make sure that the social and human perspectives are taken into account. How non-digital assets are represented on the blockchain and controlled is another concern that has ethical implications as it brings various political and legal challenges (Center, 2018).

Meanwhile, the encoding of smart contracts will need to implement social as well as legal aspects to help support new models of governance that protects human dignity and realize the human capabilities (Tang et al., 2019). Organizations need to recognize the importance of social contracts in reconciling conflicting ethical views and reflect on the importance of social values like equality and fairness. With movements like "black lives matter," corporations will be pressured to demonstrate evidence that pursuing their self-interest is not compromising the realization of social values.

With respect to AI, organizations need to recognize that while the technology can perform and possibly outperform humans on specific tasks, it lacks the general 
characteristics of self-understanding, self-control, self-consciousness and selfmotivation (Lu et al., 2018) which could result in the violation of ethical principles such as safety and non-maleficence. Another ethical concern is the exploiting power that accounting firms will gain over customers. As the accountants accumulate big data, the extracted knowledge becomes an exclusive asset where customers will not benefit from the pooled data (Tang et al., 2019). In addition, small and medium size enterprises are likely to be at a disadvantage of benefiting from these technologies and big data, given the high cost associated with developing the IT infrastructure and its computational resources. This will undermine the network effects organizations are likely to gain from massive adoption to ensure security of the data (Singh et al., 2020).

Given IoT real-time monitoring capabilities, some of the information collected can be personal posing privacy threats to organizations. Accordingly, organizations will need to disclose such information to employees and get their written consent on the possible collection of private data. Employees will need to understand the objectives of adopting the technologies and the possible risks or inconveniences the technology can pose.

We expect accountants to play a critical role in the near future to guide and influence how emergent technologies become an integral part of the standardized and optimized financial system (ICAEW, 2017). Accountants will have to examine the changes that need to be incorporated within the accounting standards to endorse the verifiability and transparency of blockchain-based, IoT-enabled and AIempowered accounting ecosystem (Dai et al., 2017). Accountants will also have to advise on how best to setup and join the technologies to avoid ethical blindness balancing between the costs and benefits of the new system. The engagement of accountants in defining these laws and regulations is critical in order for such organizational disclosure to be legitimate (Moll \& Yigitbasioglu, 2019).

The social implications of the technologies on accountant's self-efficacy and perceptions of job security will also need to be studied. Do these emerging technologies pose a threat to accounting jobs? Will accountants be excluded from certain tasks? Will the exclusion require retraining accountants to focus more on auditing AI software to validate its objectivity? Can accountants benefit from the 
interaction with the machine? Can it improve their ethical decision-making? Can information generated by AI be used to condemn accountant's conduct? Can the technology be designed to respect the cognitive capabilities of experts?

Futures studies need to address how these technologies and their combination will curtail the ethical blindness of accountants and whether humans can override the technology and act independently from the recommendation of the so-called artificially intelligent machine.

\section{CONCLUSIONS}

In this paper, we discussed the potential effect of three emerging technologies on reducing ethical blindness in accounting decision making. In our discussion, we covered the independent effects of each technology on accounting ethical standards and the challenges that each may pose to the accounting profession. While some of these challenges can be overcome by adopting all three technologies, special attention needs to be given to the social and legal implications.

In our discussion of the blockchain, we maintained that the decentralized and immutable architecture will help ensure the integrity of all transactions and provide the transparency needed to build trust in the accounting ecosystem. With respect to IoT, the real time capabilities of the technology will allow automatic data collection and greater visibility into asset evaluation and tracking. A major concern of IoT is security and the threat of single point of failure. The use of AI in accounting had already generated tangible benefits in augmenting the intelligence of accountants to analyse voluminous data and avoid intentional and unintentional fraud activities. However, a clear division of labour between accountants and AI needs to be established and AI reasoning need to be transparent to insure fairness and objectivity to all.

While each technology by itself helps accountants uphold some ethical standards while compromising others, the combinative effect of the three technologies helps create rule-based ethical standards that minimize the risks of aggressive reporting. The encoding of social contracts that promote equity and fairness will ensure that the standards abide by the rule of the land while maintaining human dignity. Thus, 
the involvement of accountants in developing practical guidance and effective governance of these technologies will be crucial.

\section{REFERENCES}

ACFE. (2018). Report to the Nations 2018 Global study on occupational fraud and abuse. https://www.acfe.com/report-to-the-nations/2018/default.aspx

ACFE. (2019). Anti-Fraud Technology Benchmarking Report. https://www.acfe.com/technology-benchmarking-report.aspx Accessed 1 January 2020

Amernic, J. H., \& Craig, R. J. (2010). Accounting as a facilitator of extreme narcissism. Journal of Business Ethics, 96(1), 79-93. https://doi.org/10.1007/s10551-010-0450-0

Andersen, N. (2016). Blockchain technology: A game-changer in accounting (Deloitte, March, Issue. https://www2.deloitte.com/content/dam/Deloitte/de/ Documents/Innovation/Blockchain_A\%20game-changer\%20in\%20accounting. pdf Accessed 1 February 2020

Apte, S., \& Petrovsky, N. (2016). Will blockchain technology revolutionize excipient supply chain management? Journal of Excipients and Food Chemicals, 7(3), 910.

Aquino, K., Freeman, D., Reed II, A., Lim, V. K., \& Felps, W. (2009). Testing a social-cognitive model of moral behavior: the interactive influence of situations and moral identity centrality. Journal of personality and social psychology, 97(1), 123. https://doi.org/10.1037/a0015406

Baum, S. D. (2020). Social choice ethics in artificial intelligence. AI \& SOCIETY, 35(1), 165-176. https://doi.org/10.1007/s00146-017-0760-1

Beerbaum, D., \& Puaschunder, J. M. (2019). A behavioral economics approach to digitalization: The case of a principles-based taxonomy. In Intergenerational Governance and Leadership in the Corporate World: Emerging Research and Opportunities (pp. 107-122). IGI Global.

Bible, W., Raphael, J., Taylor, P., \& Valiente, I. O. (2017). Blockchain technology and its potential impact on the audit and assurance profession (Aicpa. org, Issue. https://www.aicpa.org/content/dam/aicpa/interestareas/frc/assuranceadvisoryservi ces/downloadabledocuments/blockchain-technology-and-its-potential-impact-onthe-audit-and-assurance-profession.pdf 
Board, F. A. S. (2020). https://www.fasb.org/home

Bostrom, N., \& Yudkowsky, E. (2014). The ethics of artificial intelligence. The Cambridge handbook of artificial intelligence, 1, 316-334.

Brandon, D. (2016). The blockchain: The future of business information systems. International Journal of the Academic Business World, 10(2), 33-40.

Brown, N. C., Crowley, R. M., \& Elliott, W. B. (2020). What are you saying? Using topic to detect financial misreporting. Journal of Accounting Research, 58(1), 237291. https://doi.org/10.1111/1475-679X.12294

Cao, L.-J., \& Tay, F. E. H. (2003). Support vector machine with adaptive parameters in financial time series forecasting. IEEE Transactions on neural networks, 14(6), 1506-1518. https://doi.org/10.1109/TNN.2003.820556

Casino, F., Dasaklis, T. K., \& Patsakis, C. (2019). A systematic literature review of blockchain-based applications: current status, classification and open issues. Telematics and Informatics, 36, 55-81. https://doi.org/10.1016/j.tele.2018.11.006

Cellan-Jones, R. (2017). Google DeepMind: AI becomes more alien. https://www.bbc.com/news/technology-41668701

Center, B. (2018). The Blockchain Ethical Design Framework. https://repository. library.georgetown.edu/bitstream/handle/10822/1051505/Blockchain-EthicalDesign-Framework_BeeckCenter.pdf?sequence=1 Accessed 25 June 2020

Center for Audit Quality (2010). Quality, C. f. A. (2021). https://www.thecaq.org/ CGMA, C. (2018). Blockchain augmented audit-Benefits and challenges for accounting professionals. The Journal of Theoretical Accounting Research, 14(1), 117-137.

Chui, M., Löffler, M., \& Roberts, R. (2010). The internet of things. McKinsey Quarterly, 2(2010), 1-9.

Cialdini, R. B., Reno, R. R., \& Kallgren, C. A. (1990). A focus theory of normative conduct: recycling the concept of norms to reduce littering in public places. Journal of personality and social psychology, 58(6), 1015. https://doi.org/10.1037/00223514.58.6.1015

Coleman, J. W. (1987). Toward an integrated theory of white-collar crime. American journal of Sociology, 93(2), 406-439. https://doi.org/10.1086/228750 
Commerford, B. P., Dennis, S. A., Joe, J. R., \& Wang, J. J. A. a. S. (2019). Complex estimates and auditor reliance on artificial intelligence. https://doi.org/10.2139/ssrn.3422591

Cressey, D. R. (1953). Other people's money; a study of the social psychology of embezzlement. Glencoe, IL:The Free Press. https://doi.org/10.2307/2087778

Dai, J., \& Vasarhelyi, M. A. (2016). Imagineering Audit 4.0. Journal of Emerging Technologies in Accounting, 13(1), 1-15. https://doi.org/10.2308/jeta-10494

Dai, J., Wang, Y., \& Vasarhelyi, M. A. (2017). Blockchain: an emerging solution for fraud prevention. The CPA Journal, 87(6), 12-14.

Davenport, T. H., \& Kirby, J. (2016). Only humans need apply: Winners and losers in the age of smart machines. Harper Business New York, NY.

Dellaportas, S. (2013). Conversations with inmate accountants: Motivation, opportunity and the fraud triangle. Accounting forum, 37(1), 29-39. https://doi.org/10.1016/j.accfor.2012.09.003

Dellermann, D., Calma, A., Lipusch, N., Weber, T., Weigel, S., \& Ebel, P. (2019). The future of human-AI collaboration: a taxonomy of design knowledge for hybrid intelligence systems. Proceedings of the 52nd Hawaii International Conference on System Sciences,

Ding, K., Lev, B., Peng, X., Sun, T., \& Vasarhelyi, M. A. (2019). Machine learning improves accounting estimates. Available at SSRN 3253220. http://dx.doi.org/10.2139/ssrn.3253220

Dorminey, J. W., Fleming, A. S., Kranacher, M.-J., \& Riley Jr, R. A. (2010). Beyond the fraud triangle. The CPA Journal, 80(7), 17.

Düdder, B., \& Ross, O. (2017). Timber tracking: reducing complexity of due diligence by using blockchain technology. Available at SSRN 3015219. https://doi.org/10.2139/ssrn.3015219

Epley, N., \& Caruso, E. M. (2004). Egocentric ethics. Social Justice Research, 17(2), 171-187. https://doi.org/10.1023/B:SORE.0000027408.72713.45

Fanning, K. M., \& Cogger, K. O. (1998). Neural network detection of management fraud using published financial data. Intelligent Systems in Accounting, Finance \& Management, 7(1), 21-41. https://doi.org/10.1002/(SICI)1099-1174(199803)7:1

Faraj, S., Pachidi, S., \& Sayegh, K. (2018). Working and organizing in the age of the learning algorithm. Information and Organization, 28(1), 62-70. https://doi.org/10.1016/j.infoandorg.2018.02.005 
Fisher, K. (2015). The Psychology of Fraud: What Motivates Fraudsters to Commit Crime? Available at SSRN 2596825. https://doi.org/10.2139/ssrn.2596825

Friess, P. (2016). Digitising the industry-internet of things connecting the physical, digital and virtual worlds. River Publishers. https://doi.org/10.13052/rp9788793379824

Galarza, M. (2017). The changing nature of accounting. Strategic Finance, 98(8), 50.

Galeshchuk, S., \& Mukherjee, S. (2017). Deep networks for predicting direction of change in foreign exchange rates. Intelligent Systems in Accounting, Finance and Management, 24(4), 100-110. https://doi.org/10.1002/isaf.1404

Hall, K. (2009). Why good intentions are often not enough: The potential for ethical blindness in legal decision-making. REAFFIRMING LEGAL ETHICS: TAKING STOCK AND NEW IDEAS, Reid Mortensen, Michael Robertson, Lillian Corbin, Francesca Bartlett, Kieran Tranter, eds., Routledge, Forthcoming, 09-32.

Heber, D., \& Groll, M. (2017). Towards a digital twin: How the blockchain can foster E/E-traceability in consideration of model-based systems engineering. DS 87-3 Proceedings of the 21st International Conference on Engineering Design (ICED 17) Vol 3: Product, Services and Systems Design, Vancouver, Canada, 2125.08. 2017,

ICAEW. (2017). Blockchain and the future of accountancy. https://www.icaew.com/technical/technology/blockchain/blockchainarticles/blockchain-and-the-accounting-perspective Accessed 25 June 2020

ICAEW. (2019). The internet of things and accounting: lessons from China. https://www.icaew.com/technical/technology/data/internet-of-things-andaccounting Accessed 20 June 2020

Issa, H., Sun, T., \& Vasarhelyi, M. A. (2016). Research ideas for artificial intelligence in auditing: The formalization of audit and workforce supplementation. Journal of Emerging Technologies in Accounting, 13(2), 1-20. https://doi.org/10.2308/jeta-10511

Joffe-Walt, C., \& Spiegal, A. (2012). The psychology of fraud: Why good people do bad things. NPR. In.

Kahneman, D., \& Tversky, A. (2013). Prospect theory: An analysis of decision under risk. In Handbook of the fundamentals of financial decision making: Part I (pp. 99-127). World Scientific. https://doi.org/10.1142/9789814417358_0006 
Kakavand, H., Kost De Sevres, N., \& Chilton, B. (2017). The blockchain revolution: an analysis of regulation and technology related to distributed ledger technologies. Available at SSRN 2849251. https://doi.org/10.2139/ssrn.2849251

Karmann, T., Mauer, R., Flatten, T. C., \& Brettel, M. (2016). Entrepreneurial orientation and corruption. Journal of Business Ethics, 133(2), 223-234. https://doi.org/10.1007/s10551-014-2305-6

Kelly, K., \& Murphy, P. R. (2019). Reducing Accounting Aggressiveness with General Ethical Norms and Decision Structure. Journal of Business Ethics, 1-17. https://doi.org/10.1007/s10551-019-04290-w

Kokina, J., Mancha, R., \& Pachamanova, D. (2017). Blockchain: Emergent industry adoption and implications for accounting. Journal of Emerging Technologies in Accounting, 14(2), 91-100. https://doi.org/10.2308/jeta-51911

Kokina, J., \& Kozlowski, S. (2016). The next frontier in data analytics. Journal of Accountancy, 222(2), 58.

KPMG. (2017). Rise of the Humans: The Integration of Digital and Human Labor. https://advisory.kpmg.us/articles/2017/rise-of-the-humans-1.html Accessed 10 August 2020

KPMG. (2018). Auditing Blockchain Solution. https://home.kpmg/in/en/home/ insights/2018/10/audit-blockchain-approach-methodology.html Accessed 1 September 2020

Krahel, J. P., \& Titera, W. R. (2015). Consequences of Big Data and formalization on accounting and auditing standards. Accounting Horizons, 29(2), 409-422. https://doi.org/10.2308/acch-51065

Kranacher, M.-J., \& Riley, R. (2019). Forensic accounting and fraud examination. John Wiley \& Sons.

Kunda, Z. (1990). The case for motivated reasoning. Psychological bulletin, 108(3), 480. https://doi.org/10.1037/0033-2909.108.3.480

Laing, G. K. (2016). Violations of Economic Rational Decision Making: the Influence of Framing on the Cognitive Perceptions of Accountants. e-Journal of Social \& Behavioural Research in Business, 7(2), 1.

Lam, M. (2004). Neural network techniques for financial performance prediction: integrating fundamental and technical analysis. Decision support systems, 37(4), 567-581. https://doi.org/10.1016/S0167-9236(03)00088-5 
Lindqvist, U., \& Neumann, P. G. (2017). The future of the Internet of Things. Communications of the ACM, 60(2), 26-30. https://doi.org/10.1145/3029589

Lu, H., Li, Y., Chen, M., Kim, H., \& Serikawa, S. (2018). Brain intelligence: go beyond artificial intelligence. Mobile Networks and Applications, 23(2), 368-375. https://doi.org/10.1007/s11036-017-0932-8

Lu, Q., \& Xu, X. (2017). Adaptable blockchain-based systems: A case study for product traceability. IEEE Software, 34(6), 21-27. https://doi.org/10.1109/MS.2017.4121227

Luo, J., Meng, Q., \& Cai, Y. (2018). Analysis of the Impact of Artificial Intelligence application on the Development of Accounting Industry. Open Journal of Business and Management, 6(4), 850-856. https://doi.org/10.4236/ojbm.2018.64063

Mansor, N. (2015). Fraud triangle theory and fraud diamond theory. Understanding the convergent and divergent for future research. International Journal of Academic Research in Accounting, Finance and Management Science, 1, 38-45. https://doi.org/10.6007/IJARAFMS/v5-3/1823

Marshall, T. E., \& Lambert, S. L. (2018). Cloud-based intelligent accounting applications: accounting task automation using IBM watson cognitive computing. Journal of Emerging Technologies in Accounting, 15(1), 199-215. https://doi.org/10.2308/jeta-52095

Menzefricke, U., \& Smieliauskas, W. (2019). Managerial Miscalibration and Its Effects on the Auditability of Accounting Estimates: Evidence from Pension Accounting. The International Journal of Accounting, 54(04), 1950016. https://doi.org/10.1142/S1094406019500161

Merriam-Webster. (2020). In Merriam-Webster.com dictionary. https://www.merriam-webster.com/dictionary/artificial\%20intelligence Accessed 1 Ocober 2020

Mistry, I., Tanwar, S., Tyagi, S., \& Kumar, N. (2020). Blockchain for 5G-enabled IoT for industrial automation: A systematic review, solutions, and challenges. Mechanical Systems and Signal Processing, 135, 106382. https://doi.org/10.1016/j.ymssp.2019.106382

Moin, S., Karim, A., Safdar, Z., Safdar, K., Ahmed, E., \& Imran, M. (2019). Securing IoTs in distributed blockchain: Analysis, requirements and open issues. Future Generation Computer Systems, 100, 325-343. https://doi.org/10.1016/j.future.2019.05.023 
Moll, J., \& Yigitbasioglu, O. (2019). The role of internet-related technologies in shaping the work of accountants: New directions for accounting research. The $\begin{array}{llll}\text { British Accounting } & \text { Review, } & \end{array}$ https://doi.org/10.1016/j.bar.2019.04.002

Munoko, I., Brown-Liburd, H. L., \& Vasarhelyi, M. (2020). The Ethical Implications of Using Artificial Intelligence in Auditing. Journal of Business Ethics, 1-26. https://doi.org/10.1007/s10551-019-04407-1

Murphy, M. L. (2015). How the Internet of Things will impact CPAs. AICPA. https://www.aicpastore.com/Content/media/PRODUCER_CONTENT/Newsletter s/Articles_2015/CPA/MAY/impact_CPAs.jsp\#: :text=The\%20IoT\%20will\%20o ne\%20day,to\%20CPA\%20firms'\%20corporate\%20clients.\&text=By\%20allowing $\% 20$ for $\% 20$ more $\% 20$ real,reduce $\% 20$ costs $\% 2 \mathrm{C} \% 20$ and $\% 20$ manage $\% 20$ risks Accessed 12 January 2020

Murphy, P. R., \& Dacin, M. T. (2011). Psychological pathways to fraud: Understanding and preventing fraud in organizations. Journal of Business Ethics, 101(4), 601-618. https://doi.org/10.1007/s10551-011-0741-0

Palazzo, G., Krings, F., \& Hoffrage, U. (2012). Ethical blindness. Journal of Business Ethics, 109(3), 323-338. https://doi.org/10.1007/s10551-011-1130-4

Parot, A., Michell, K., \& Kristjanpoller, W. D. (2019). Using Artificial Neural Networks to forecast Exchange Rate, including VAR-VECM residual analysis and prediction linear combination. Intelligent Systems in Accounting, Finance and Management, 26(1), 3-15. https://doi.org/10.1002/isaf.1440

Paschen, U., Pitt, C., \& Kietzmann, J. (2020). Artificial intelligence: Building blocks and an innovation typology. Business Horizons, 63(2), 147-155. https://doi.org/10.1016/j.bushor.2019.10.004

Polim, R., Hu, Q., \& Kumara, S. (2017). Blockchain in megacity logistics. IIE Annual Conference. Proceedings,

Protiviti. (2016). Looking Deeper into Robotic Automation: Considerations and Case Studies for Robotic Process and Desktop Automation. https://www.protiviti.com/sites/default/files/australia/insights/looking-deeperinto-robotic-automation-protiviti-global-a4_0.pdf Accessed 15 November 2020

PwC. (2017). Sizing the prize What's the real value of AI for your business and how can you capitalise? https://www.pwc.com/gx/en/issues/data-andanalytics/publications/artificial-intelligence-study.html Accessed 1 July 2020 
PwC. (2018). Pulling fraud out of the shadows Global Economic Crime and Fraud Survey 2018. https://www.pwccn.com/en/services/consulting/forensicservices/economic-crime-survey.html Accessed 1 January 2020

PwC. (2020). Fighting fraud: A never-ending battle. https://www.pwc.com/gx/en/services/advisory/forensics/economic-crimesurvey.html Accessed 1 August 2020

Rathore, S., Sharma, P. K., \& Park, J. H. (2017). XSSClassifier: An Efficient XSS Attack Detection Approach Based on Machine Learning Classifier on SNSs. Journal of Information Processing Systems, 13(4).

Rivas, V., Parras-Gutiérrez, E., Merelo, J., Arenas, M. G., \& García-Fernández, P. (2017). Time series forecasting using evolutionary neural nets implemented in a volunteer computing system. Intelligent Systems in Accounting, Finance and Management, 24(2-3), 87-95. https://doi.org/10.1002/isaf.1409

Salman, S. (2015). Auditing the Internet of Things. Internal Auditor. https://iaonline.theiia.org/2015/auditing-the-internet-of-things Accessed 12 January 2020

Schnatterly, K., Gangloff, K. A., \& Tuschke, A. (2018). CEO wrongdoing: A review of pressure, opportunity, and rationalization. Journal of Management, 44(6), 2405-2432. https://doi.org/10.1177/0149206318771177

Schuh, G., Potente, T., Wesch-Potente, C., Weber, A. R., \& Prote, J.-P. (2014). Collaboration Mechanisms to increase Productivity in the Context of Industrie 4.0. Procedia Cirp, 19, 51-56. https://doi.org/10.1016/j.procir.2014.05.016

Service, I. A. (2020). https://www.iasonline.org/ Accessed 1 September 2020

Shaw, J. (2019). Artificial intelligence and Ethics. Harvard Magazine, 30.

Shawver, T. J., \& Miller, W. F. (2017). Moral intensity revisited: Measuring the benefit of accounting ethics interventions. Journal of Business Ethics, 141(3), 587603. https://doi.org/10.1007/s10551-015-2711-4

Singh, S. K., Rathore, S., \& Park, J. H. (2020). Blockiotintelligence: A blockchainenabled intelligent IoT architecture with artificial intelligence. Future Generation Computer Systems, 110, 721-743. https://doi.org/10.1016/j.future.2019.09.002

Smieliauskas, W., Bewley, K., Gronewold, U., \& Menzefricke, U. (2018). Misleading Forecasts in Accounting Estimates: A Form of Ethical Blindness in Accounting Standards? Journal of Business Ethics, 152(2), 437-457. https://doi.org/10.1007/s10551-016-3289-1 
Snyder, C. R., \& Higgins, R. L. (1988). Excuses: Their effective role in the negotiation of reality. Psychological bulletin, 104(1), 23. https://doi.org/10.1037/0033-2909.104.1.23

Standards, I. F. R. (2020). https://www.ifrs.org/

Sutherland, E. (1947). Principles of Criminology. Philadelphia, PA: J.B. Lippincott Company.

Tang, Y., Xiong, J., Becerril-Arreola, R., \& Iyer, L. (2019). Ethics of blockchain. \%J Information Technology \& People. https://doi.org/10.1108/ITP-10-2018-0491

TheEconomist. (2014). Accounting scandals The dozy watchdogs. https://www.economist.com/briefing/2014/12/11/the-dozy-watchdogs Accessed 1 September 2020

Vaidyanathan, N. (2017). Divided We Fall, Distributed We Stand. The Professional Accountant's Guide to Distributed Ledgers and Blockchain. https://www.accaglobal.com/my/en/technical-activities/technical-resourcessearch/2017/april/divided-we-fall-distributed-we-stand.html Accessed 1 March 2020

Vasarhelyi, M. A., Alles, M., Kuenkaikaew, S., \& Littley, J. (2012). The acceptance and adoption of continuous auditing by internal auditors: A micro analysis. International Journal of Accounting Information Systems, 13(3), 267-281. https://doi.org/10.1016/j.accinf.2012.06.011

Vladu, A. B., Amat, O., \& Cuzdriorean, D. D. (2017). Truthfulness in accounting: How to discriminate accounting manipulators from non-manipulators. Journal of Business Ethics, 140(4), 633-648. https://doi.org/10.1007/s10551-016-3048-3

Winfield, A. F., Michael, K., Pitt, J., \& Evers, V. (2019). Machine ethics: the design and governance of ethical AI and autonomous systems. Proceedings of the IEEE, 107(3), 509-517. https://doi.org/10.1109/JPROC.2019.2900622

Wolfe, D. T., \& Hermanson, D. R. (2004). The fraud diamond: Considering the four elements of fraud. The CPA Journal, December, 1-5.

Zhang, Y., \& Wu, L. (2009). Stock market prediction of S\&P 500 via combination of improved BCO approach and BP neural network. Expert systems with applications, 36(5), 8849-8854. https://doi.org/10.1016/j.eswa.2008.11.028 